\title{
Kinetics and Energetics of Phosphate Release from Tropical Soils Determined by Mixed Ion-Exchange Resins
}

\author{
John O. Agbenin* and Bernardo van Raij
}

\begin{abstract}
Kinetic information on soil $P$ release is required to optimize $P$ fertilizer use efficiency in agricultural production and develop guidelines for the disposal of P-rich wastes onto the land. We determined the kinetics and energy changes of $P$ release from tropical soils by mixed ion-exchange resin. Phosphate release patterns were determined with or without shaking and at three temperatures: 298, 308, and $333 \mathrm{~K}$. Phosphate release patterns determined as $P$ uptake by the exchange resins were best described by diffusion models. The nature of diffusional limitation was discriminated on the basis of activation energies $\left(E_{\text {a }}\right)$, which ranged from 42.03 to $48.72 \mathrm{~kJ} \mathrm{~mol}^{-1}$. The range of $E_{\text {n }}$ was consistent with, and close to, $42.1 \mathrm{~kJ} \mathrm{~mol}^{-1}$ for intraparticle diffusion-controlled ion-exchange reactions. The $P$ diffusion coefficients ranged from 2.81 to $4.71 \times$ to $10^{-13} \mathrm{~m}^{2} \mathrm{~s}^{-1}$ under shaking conditions, but decreased to 1.42 to $2.68 \times 10^{-13} \mathrm{~m}^{2} \mathrm{~s}^{-1}$ for nonshaking conditions probably because of large films that developed around the resin beads under static or nonshaking conditions. The free energy of activation $\Delta G^{\text {of }}$ and entropy of activation $\Delta S^{\mathbf{0}}$ were lower than those of soils studied by means of resin bags indicating favorable $P$ exchange reactions and less stearic inhibition for the resins. The enthalpy of activation $\Delta H^{0 \ddagger}$ for the overall $P$ exchange reactions was strongly endothermic.
\end{abstract}

$\mathrm{I}$ N THE LAST 15 years, there has been a considerable amount of research on the use and adaptation of mixed ion-exchange resins for routine soil testing for macro- and micronutrients (Raij et al., 1986; Yang and Skogley, 1992; Agbenin et al., 1999). The purpose of a

J.O. Agbenin, Dep. of Soil Science, Faculty of Agriculture, Ahmadu Bello University, Zaria, Nigeria; B. van Raij, Embrapa Meio Ambiente, Caixa Postal 69, 13820-000 Jaguariuna (SP), Brazil. Received 20 July 2000. *Corresponding author (Agbenin@abu.edu.ng).

Published in Soil Sci. Soc. Am. J. 65:1108-1114 (2001). cation sink in mixed extraction of available $\mathrm{P}$ is to stimulate the dissolution of soluble and some sparingly soluble P compounds (Robinson et al., 1992) which, otherwise, would not readily participate in phosphate exchange reactions with ion-exchange resins, but are nonetheless important for residual and long-term $\mathrm{P}$ availability in soils. Soils testing and calibration with ion-exchange resins for fertilizer-P recommendation and management can be improved if the kinetic processes that regulate $P$ release from the soils and uptake by exchange resins are understood.

The kinetics of $\mathrm{P}$ release and sorption in soils is a subject of importance in soil and environmental sciences primarily because $\mathbf{P}$ uptake by plants spans over time. Thus, kinetic information is required to properly characterize the P supplying capacity of soils, to design fertilizer-P management to optimize efficiency, to reduce environmental pollution, and to develop guidelines for the disposal of P-rich wastes onto the land (Skopp, 1986). Another reason for kinetic study is to obtain information on reaction mechanisms (Skopp, 1986).

Mechanisms of $\mathrm{P}$ release and sorption reactions with soil particles are complex, considering either the types of adsorbents or the numerous kinetic expressions that have been used to describe these processes. Several reports, mainly from temperate soils, have dealt with the kinetics of $\mathrm{P}$ uptake by anion-exchange resins in soils, but the kinetic interpretations are still conflicting. Amer et al. (1955) reported that $\mathrm{P}$ adsorption by anionexchange resin from soil solution could be described by two or three simultaneous first-order rate processes, while Griffin and Jurinak (1974) reported pseudo firstorder reaction. Vaidyanathan and Talibudden (1970) showed that $\mathrm{P}$ uptake rate by ion-exchange resins in 
some British soils was limited by intraparticle diffusion, an idea rejected by Bache and Ireland (1980), who reported that $\mathrm{P}$ adsorption by anion-exchange resins in the chloride or bicarbonate form did not conform to intraparticle diffusion-controlled reaction in other British soils. Dalal (1974) concluded no mechanistic interpretation that the kinetics of $\mathrm{P}$ uptake by anion-exchange resins in some tropical soils followed a fractional rate equation. Soldano and Boyd (1953) indicated that P uptake rate in a free electrolyte solution was controlled by several simultaneous processes of film diffusion or first-order rate chemical kinetics at the surface. Yang and Skogley (1992), using resin bags, concluded that diffusion appeared to be the rate-limiting step but did not explicitly distinguish the nature of diffusional limitation. The objectives of this study were to assess the diffusion kinetics and energy relations of $P$ release from tropical soils determined by mixed resins.

\section{THEORY}

In soil-resin-solution systems, the adsorption of $\mathrm{P}$ from soils by ion-exchange resins can be limited by diffusion or chemical exchange reactions. Two types of diffusional limitation might occur: (i) diffusion through a bounding-film around the resin bead and soil particle, or (ii) diffusion within the resin particle or soil particle (intraparticle diffusion). If diffusion through a bounding-film around the resin or soil particle is rate-limiting, the rate of transfer across the film can be described by Eq. [1] (Agbenin and Raij, 1999) originally derived by Boyd et al. (1947).

$$
\mathrm{d} Q / \mathrm{d} t=k_{\mathrm{d}}\left(Q_{\infty}-Q\right)
$$

where $k_{\mathrm{d}}$ is the apparent rate of diffusion across the film, $Q$ is the amount of $\mathrm{P}$ adsorbed by resin at time $t$, and $Q_{\infty}$ is equilibrium adsorption. Data of $P$ uptake by ion-exchange resins obeying Eq. [1] does not conclusively exclude chemical exchange reaction as the rate-limiting step since an equivalent expression can be derived from the law of mass action. For example, consider a monovalent exchange reaction between $\mathrm{Cl}^{-}$charged resin and $\mathrm{H}_{2} \mathrm{PO}_{4}^{-}$in soil solution as follows:

$$
\mathrm{R}-\mathrm{Cl}+\mathrm{H}_{2} \mathrm{PO}_{4}^{-} \leftrightarrow \mathrm{Cl}^{-}+\mathrm{R}-\mathrm{H}_{2} \mathrm{PO}_{4}
$$

if $m_{\mathrm{H}_{2} \mathrm{PO}_{4}^{-}}$and $m_{\mathrm{Cl}^{-}}$are the concentrations of $\mathrm{H}_{2} \mathrm{PO}_{4}^{-}$and $\mathrm{Cl}^{-}$ in solution. and $n_{\mathrm{R}-\mathrm{H}_{2} \mathrm{PO}_{4}}$ and $n_{\mathrm{R}-\mathrm{Cl}}$ are the moles of $\mathrm{H}_{2} \mathrm{PO}_{4}^{-}$and $\mathrm{Cl}$ adsorbed by resin, following Boyd et al. (1947), the amount of $\mathrm{P}$ uptake by the resins at time $t$ can be written as:

$n_{\mathrm{R}-\mathrm{H}_{2} \mathrm{PO}_{4}}=\frac{k_{1} M_{\mathrm{H}_{2} \mathrm{PO}_{4}}+E}{k_{1} m_{\mathrm{H}_{2} \mathrm{PO}_{4}}+k_{2} m_{\mathrm{Cl}}}\left[1-\exp \left(-k_{\mathrm{e}} t\right)\right]=Q$

where $\mathrm{E}=n_{\mathrm{R}-\mathrm{H}_{2} \mathrm{PO}_{4}}+n_{\mathrm{R}-\mathrm{Cl}}, k_{e}=k_{1} m_{\mathrm{H}_{1} \mathrm{PO}_{4}}+k_{2} n_{\mathrm{R}-\mathrm{Cl}}$, and $k_{1}$ and $k_{2}$ are the forward and backward rate, respectively. At equilib- rium adsorption $Q_{n}$, Eq. [3] can be simplified (Boyd et al., 1947) to:

$$
Q_{\infty}-Q=Q_{\infty} \exp \left(-k_{\mathrm{e}} t\right)
$$

where $k_{\mathrm{e}}$ is the exchange rate constant. Note that Eq. [4] is the integrated form of Eq. [1]; hence kinetic data obeying Eq. [1] does not exclude exchange reaction as the rate-limiting step.

Theory of intraparticle diffusion of ions in ion-exchange resins was well developed by Boyd et al. (1947). The fractional equilibrium adsorption of $\mathrm{P}$ diffusing through a spherical particle of radius $r_{0}$ with initially uniform concentration, and with the surface concentration of the diffusing ion assumed constant can be described by Eq. [5].

$$
\frac{Q}{Q_{\infty}}=1-\frac{6}{\pi^{2}} \sum_{n=1}^{-} \frac{1}{n^{2}} \exp \left(\frac{D \pi^{2} n^{2} t}{r_{0}^{2}}\right)
$$

where $D$ is the diffusion coefficient, $\boldsymbol{n}$ is any natural number, $\pi$ is a constant, and all other terms are as defined above. If the concentration of the diffusing ion at the surface is assumed constant, one form of solution to Fick's second law applicable to diffusion in solids is the parabolic expression (Crank, 1975; Aharoni and Sparks, 1991).

$$
Q / Q_{\infty}=k_{\mathrm{d}} t^{1 / 2}
$$

\section{MATERIALS AND METHODS}

\section{Experimental Soils}

Four soils from the State of Sao Paulo, Brazil, were used for the study. Selected properties of the soils are given in Table 1. The soil $\mathrm{pH}$ was determined in $0.01 \mathrm{M} \mathrm{CaCl}_{2}$. Exchangeable $\mathrm{Ca}, \mathrm{Mg}$, and $\mathrm{K}$ were displaced by neutral ammonium acetate. Calcium and $\mathrm{Mg}$ in the extracts were determined by atomic absorption spectrometry (AAS) and $\mathrm{K}$ by flame photometry. Organic $\mathrm{C}$ was determined by dichromate oxidation technique, while cation-exchange capacity was the summation of exchangeable bases and total exchangeable acidity $(\mathrm{H}+\mathrm{Al})$. Details of analytical methods are described in Page et al. (1982). Oxalate $\mathrm{Fe}\left(\mathrm{Fe}_{\mathrm{o}}\right)$ and dithionite citrate bicarbonate $\mathrm{Fe}\left(\mathrm{Fe}_{\mathrm{d}}\right)$ were determined by the methods described by McKeague and Day (1966) and Mehra and Jackson (1960). Some properties of the experimental soils and their classification in U.S. soil taxonomy at the order level are given in Table 1.

\section{Resin Characteristics and Experimental Details}

The ion-exchange resins were a strong base anion-exchange resin (Amberlite IRA-400) and a strong acid cation-exchange resin (Amberlite IRA-120) (Rohm and Haas, Philadelphia, PA). The Amberlite IRA- 400 has an anion-exchange capacity of $140 \mathrm{cmol}_{\mathrm{c}} \mathrm{dm}^{-3}$ and Amberlite-120 has a cation-exchange

\begin{tabular}{|c|c|c|c|c|c|c|c|c|c|}
\hline \multirow[b]{2}{*}{ Soil $\dagger$} & \multirow[b]{2}{*}{$\mathrm{pH}+$} & \multirow[b]{2}{*}{$\mathbf{O C} \ddagger$} & \multicolumn{3}{|c|}{ Exchangeable cations } & \multirow[b]{2}{*}{ CEC $\ddagger$} & \multirow[b]{2}{*}{$\mathbf{F E}$. } & \multirow[b]{2}{*}{$\mathbf{F E}_{\mathbf{d}}$} & \multirow[b]{2}{*}{ Av. $\mathbf{P}$} \\
\hline & & & $\mathrm{Ca}$ & $\mathbf{M g}$ & K & & & & \\
\hline & & $\mathrm{g} \mathrm{dm}^{-3}$ & $\longrightarrow$ & $\ldots$ & $n^{-3}-$ & - & $\longrightarrow$ & - & $\mathbf{m g} \mathbf{d m}^{-3}$ \\
\hline Soil 2: Inceptisol & 6.1 & 60 & 166 & 34 & 7.0 & 232 & 1.35 & 111 & 11 (16) \\
\hline Soil 3: Ultisol & 5.3 & 22 & 22 & 6 & 4.1 & 52 & 0.48 & 11.6 & 15 (19) \\
\hline Soil 4: Ultisol & 5.9 & 22 & 41 & 16 & 8.9 & 84 & 0.48 & 13.7 & $50(72)$ \\
\hline
\end{tabular}
capacity of $195 \mathrm{cmol}_{\mathrm{c}} \mathrm{dm}^{-3}$. The cation- and anion-exchange resins have one monofunctional active site, each made of $\mathrm{N}$-alkyl group for the anion exchange resin, and sulfonic acid

Table 1. Selected physicochemical properties of the soils used in the study.

+ Classification of Soil 2 in U.S. soil taxonomy is uncertain. It is only an approximation from the Brazilian classification system.

$\ddagger$ Values of pH, OC, and CEC were from Agbenin and Raij (1999).

$\$$ Available $\mathbf{P}$ in parentheses were determined by the Melich-1 method. 
group for the cation-exchange resin with standard crosslinking. The resin particle size $\left(r_{0}\right)$ was $0.5 \mathrm{~mm}$. The resin were presaturated with $\mathrm{Na}^{+}$and $\mathrm{HCO}_{3}^{-}$following the procedure described in details by Agbenin and Raij (1999) and Agbenin et al. (1999).

Bicarbonate charged resin buffered at $\mathrm{pH} 8.5$ has been the standard extraction method for available P since 1983 (Raij et al., 1986). We chose $\mathrm{HCO}_{3}^{-}$charged resins for $\mathrm{P}$ extraction, apart from their giving strong correlation with plant uptake and responses to applied $\mathrm{P}$ in Brazilian soils, because $\mathrm{HCO}_{3}^{-}$ions buffer the soil suspension against $\mathrm{pH}$ fluctuation during the extraction process.

Twenty-five cubic centimeters of deionized water were added to $2.5 \mathrm{~cm}^{3}$ of air-dried and sieved $<2-\mathrm{mm}$ soil. A glass marble (1.8-cm diam.) was added. The flask was stoppered and agitated for $15 \mathrm{~min}$ in a rotatory motion shaker at 220 cycles per minute to disaggregate the soils with a view to facilitating separation of resins from soil particles. The glass marble was removed and $2.5 \mathrm{~cm}^{3}$ of mixed cation- and anionexchange resins presaturated with $\mathrm{Na}^{+}$and $\mathrm{HCO}_{3}^{-}$were added to the soil suspension. Two batches were prepared for shaking and nonshaking with two replicates. The sample set for agitation was transferred to the shaker, while the stationary set (nonshaking) was left on a laboratory bench.

Initial kinetic runs were made up to $96 \mathrm{~h}$ at a laboratory temperature of $22+2^{\circ} \mathrm{C}$. The soil-resin suspension was transferred with jet stream of water into a $0.4-\mathrm{mm}$ polyester netting sieve to separate resin from soil. Phosphate sorption by mixed ion-exchange resins was also carried out at 298,308 , and $333 \mathrm{~K}$ in a thermostatically controlled water following the procedure outlined above, except that agitation was less vigorous in the waterbath, and an 8 -h time scale was chosen for this experiment to avoid leaving the waterbath on overnight for safety reasons. The resin was rinsed with deionized water to remove any soil particles and transferred into a clean polystyrene flask and extracted with acidified $\mathrm{NH}_{4} \mathrm{Cl}\left(1 \mathrm{M} \mathrm{NH}_{4} \mathrm{Cl}\right.$ in $\left.0.1 \mathrm{MHCl}\right)$. Phosphate in the extract was determined colorimetrically by the method of Murphy and Riley (1962).

All kinetic runs were made in duplicate, and where variability between dulcet results exceeded $5 \%$, the duplicate analysis was repeated. In some cases, two to three repetitions were carried out for each adsorption point to obtain consistent results. The means of duplicate analyses were reported.

\section{Data Analysis}

The fit of Eq. [1], [4] and [6] to the time-dependent $P$ release patterns was assessed by $R^{2}$ and standard error (SE). Equations [1] and [4] were linearized by fitting $\log \left(1-Q^{\prime}\right.$ $\left.Q_{\infty}\right)$ vs. $t$ with a slope determined by $\left(k_{\mathrm{e}} / 2.303\right)$ (Boyd et al., 1947; Agbenin and Raij, 1999).

Because of the infinite series in Eq. [5], a numerical solution was found. Thus, by solution to this equation for spherical particles, values of $D \pi^{2} t / r_{\text {o }}^{2}$ as a function of $Q / Q_{\infty}$ were determined (Table 2). The value of $D \pi^{2} t / r_{0}^{2}$ for each experimental $Q / Q_{\infty}$ was interpolated from Table 2 (Keay and Wild, 1961) from which the internal diffusion coefficients were calculated. For intraparticle diffusion-controlled ion-exchange reactions, the rate parameter $D \pi^{2} / r_{0}^{2}$ or $D \pi_{l}^{2} / r_{0}^{2}$ divided by the reaction time $t$ is constant for each experimental $Q / Q_{\infty}$ value up to 0.80 , beyond which experimental errors become magnified (Boyd et al., 1947).

The effect of temperature of $P$ release from soils was assessed by the Arrhenius equation:

$$
k=A \exp \left(-E_{\mathrm{a}} / R T\right)
$$

where $k$ is the rate of $\mathrm{P}$ release, $A$ is a constant, and $E_{\mathrm{a}}$ is the activation energy, $R$ is the universal gas constant, and $T$ is
Table 2. Solution to Eq. [5] showing the rate parameter $\left(D \pi^{2} t / r_{0}^{2}\right)$ for each fractional equilibrium attainment $\left(Q Q_{-}\right)$for spherical particles.

\begin{tabular}{lccc}
\hline$\underline{Q}$ & $\frac{D \pi^{2} t}{r_{*}^{2}}$ & $\frac{Q}{Q_{*}}$ & $\frac{D \pi^{2} t}{r_{*}^{2}}$ \\
\hline 0.05098 & 0.0023 & 0.50001 & 0.3015 \\
0.08030 & 0.0058 & 0.55003 & 0.3823 \\
0.09045 & 0.0074 & 0.60001 & 0.4787 \\
0.10003 & 0.0091 & 0.65003 & 0.5943 \\
0.15011 & 0.0211 & 0.70001 & 0.7339 \\
0.20021 & 0.0387 & 0.75001 & 0.95051 \\
0.25002 & 0.0623 & 0.80000 & 1.1204 \\
0.30004 & 0.0928 & 0.85000 & 1.4031 \\
0.35006 & 0.1309 & 0.90000 & 1.8060 \\
0.40002 & 0.1775 & 0.95000 & 2.4981 \\
0.45003 & 0.2339 & 0.98000 & 3.4141 \\
\hline
\end{tabular}

temperature (K). When kinetic data obey the Arrhenius equation, a plot of $1 \mathrm{n} k$ as a function of the reciprocal of temperature $(1 / T)$ is linear, and $E_{\mathrm{a}}$ is calculated from the slope of regression line.

The rate coefficient is related to free energy of activation $\Delta G^{\text {oł }}$ (Adamson, 1969):

$$
k_{\mathrm{d}}=\kappa T / h \exp \left(-\Delta G^{\mathrm{O}} / R T\right)
$$

where $k$ is Bolzmann constant, $h$ is the Planck's constant, and $R$ and $T$ have their usual meanings. From the Eyring rate theory (Laidler, 1965), the entropy of activation $\left(\Delta S^{\circ}\right)$ can be calculated from the rate constant [Eq. 9] or from its relation with $\Delta G^{0 \ddagger}[\mathrm{Eq}$. 10]

$$
\begin{aligned}
k_{\mathrm{d}} & =\kappa T / h \exp \left(-\Delta S^{\mathrm{O}} / R \exp \left(-\Delta H^{\mathrm{O}} / R T\right)\right. \\
\Delta G^{\mathrm{O}} & =\Delta H^{\mathrm{O} \ddagger}-T \Delta S^{\mathrm{O} \ddagger}
\end{aligned}
$$

where $\Delta H^{\text {ot }}$ is the enthalpy of activation calculated from its relation with $E_{\mathrm{a}}$ [Eq. 11] as given by Griffin and Jurinak (1974) or with $\Delta G^{\mathrm{O}}$ and $\Delta S^{\mathrm{O \dagger}}[\mathrm{Eq}$. 10]

$$
\Delta G^{\mathrm{O} \ddagger}=E_{\mathrm{a}}-R T
$$

\section{RESULTS AND DISCUSSION}

\section{Time-Dependent Phosphate Release}

With the initial kinetic runs up to $96 \mathrm{~h}$, equilibrium $\mathrm{P}$ uptake by the resins was slowly approached by $20 \mathrm{~h}$. With the nonshaking experiment, $P$ uptake by the mixed ion resins continued, but not significantly so after $32 \mathrm{~h}$ (Fig. 1). Before $15 \mathrm{~min}$, there was no measurable $P$ desorption with the nonshaking batch especially for Soil 1 and Soil 4 in contrast to the shaking. On the basis of these initial results, $5 \mathrm{~min}$ to 24 -h reaction period was selected for shaking, and $15 \mathrm{~min}$ to $32 \mathrm{~h}$ for nonshaking batch. The equilibrium release $\left(Q_{\infty}\right)$ used for our analysis was taken to be the P uptake between 24 and $96 \mathrm{~h}$ with shaking, and between 32 and $96 \mathrm{~h}$ without shaking. Shaking increased the desorption of labile $\mathbf{P}$ in Soil 1 and Soil 4, but had no substantial effect in Soil 2 and Soil 3 as determined by resin $P$ uptake.

The $P$ release patterns determined by the mixed ionexchange resins were better modeled by the parabolic expression (Fig. 2) than by film-diffusion equation as judged from $R^{2}$ and SE values (Table 3). Since linear relations were found between $P$ sorbed by the mixed resins and the square root of time, the implied boundary conditions for deriving the parabolic expression can be 

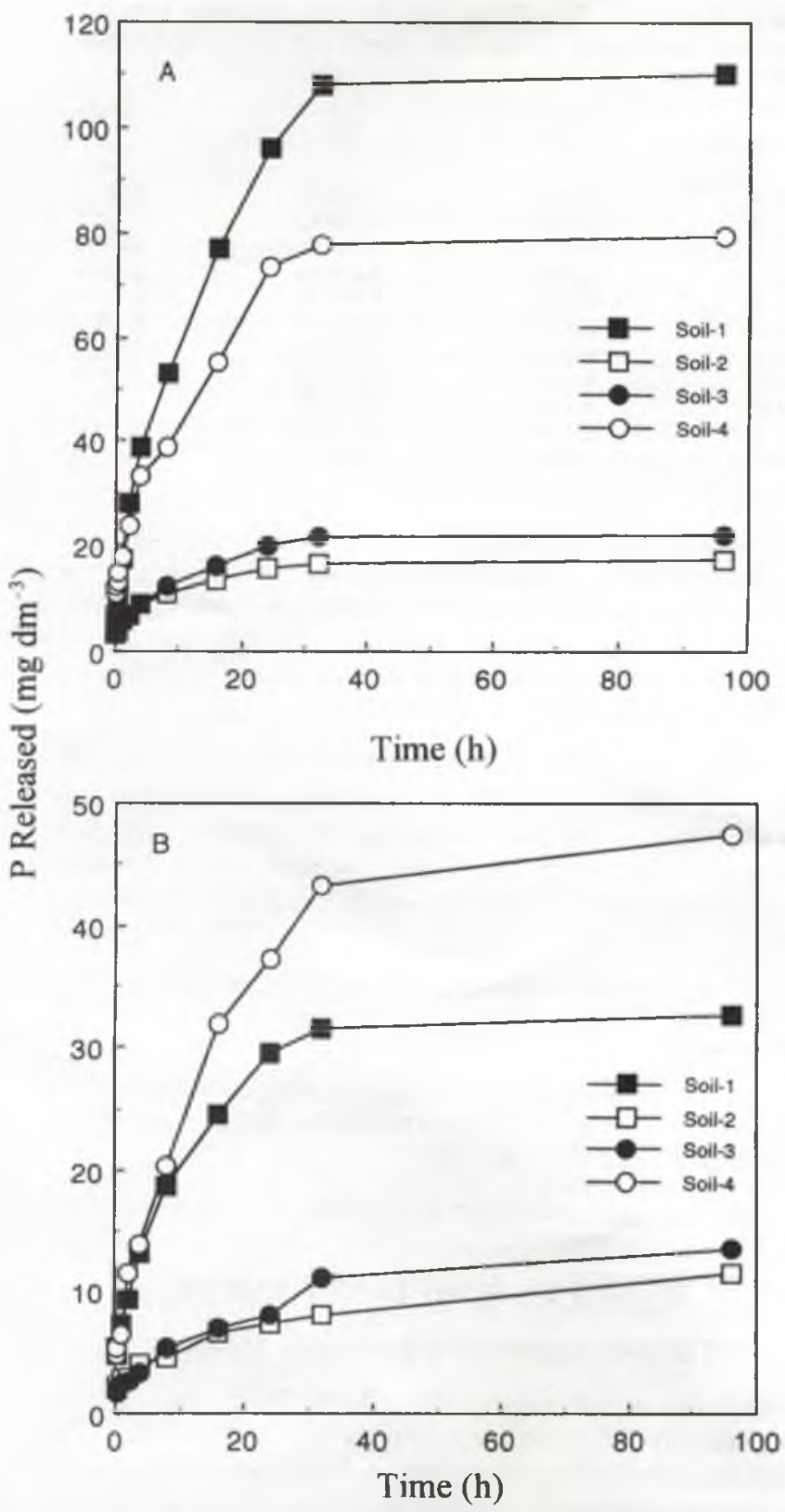

Fig. 1. The time-dependent phosphate sorption by mixed cationanion exchange resins. ( $\mathrm{A}=$ shaking and $\mathrm{B}=$ nonshaking.)

considered fulfilled (Bruemmer et al., 1988), and the kinetics of the P uptake process was most likely limited by intraparticle diffusion. However, conformity to a parabolic model cannot conclusively support intraparticle diffusion mechanism (Skopp, 1986).

The fairly constant values of $D \pi^{2} / r_{0}^{2}$ for experimental $Q / Q$. values up to 0.80 (Table 4 ), especially under shaking conditions further supported intraparticle diffusion mechanism. The mean diffusion coefficients $(D)$ ranged from 2.81 to $4.71 \times 10^{-13} \mathrm{~m}^{2} \mathrm{~s}^{-1}$ for the shaking experiment, and 1.42 to $2.68 \times 10^{-13} \mathrm{~m}^{2} \mathrm{~s}^{-1}$ for nonshaking (Table 4). These $D$ values were $10^{4}$ times lower than the diffusion of $\mathbf{P}$ in solution, but are fairly consistent with $\mathbf{P}$ diffusion in soil solids ranging from $10^{-13}$ and $10^{-14} \mathrm{~m}^{2} \mathrm{~s}^{-1}$ (Nye, 1979). The $\mathrm{D}$ values also compared favorably with 0.9 to $4.8 \times 10^{-13} \mathrm{~m}^{2} \mathrm{~s}^{-1}$ for $\mathrm{P}$ diffusion
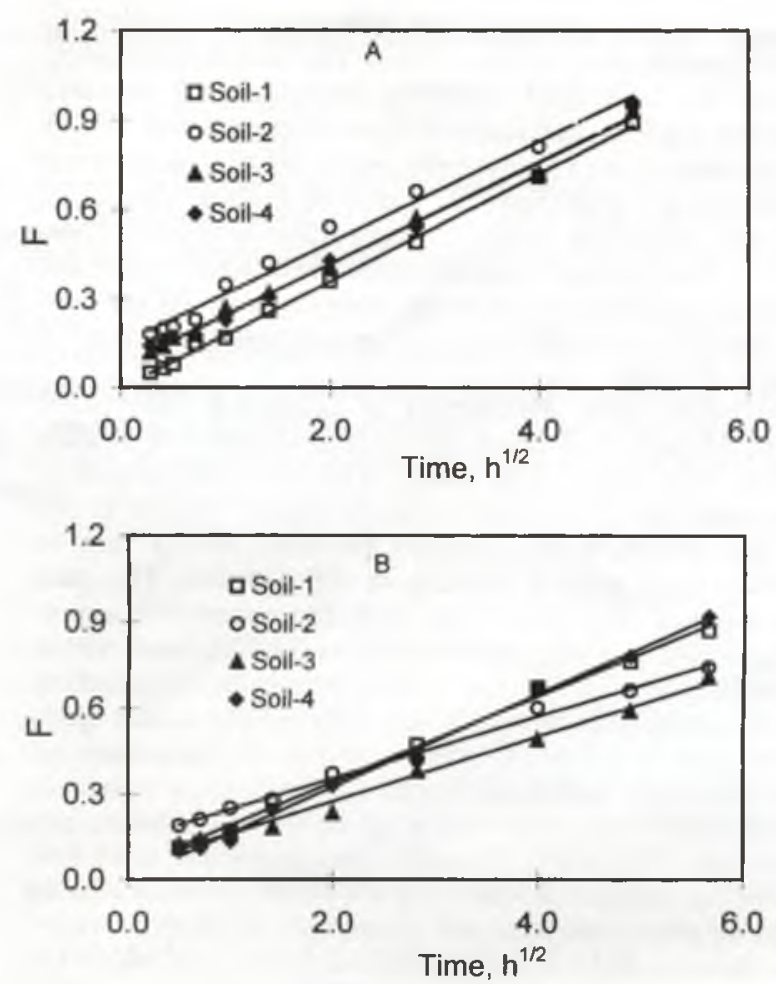

Fig. 2. Phosphate-sorption kinetics by mixed cation-anion exchange resins as described by the parabolic model $(A=$ shaking and $B=$ nonshaking) where $F$ is fractional equilibrium plotted as a function of the square root of time (h).

coefficients in mixed Amberlite IRA-Cl anion exchange resins (Rohm and Haas) and Zeocarb 225-Na cation exchange resin (Zeotech, Albuquerque, NM) in United Kingdom soils (Vaidyanathan and Talibudeen, 1970), but were, however, lower than the self-diffusion coefficient of $P\left(5.70 \times 10^{-12}\right.$ to 8.9 to $\left.10^{-10} \mathrm{~m}^{2} \mathrm{~s}^{-1}\right)$ in Dowex-2 ion exchanger resins (Dow Chemical, Midland, MI) in a free electrolyte solution (Soldano and Boyd, 1953) probably because of the viscosity of soil solution compared with a free $\mathbf{P}$ solution. Further, the counter diffusion of $\mathrm{P}\left(\mathrm{HPO}_{4}^{2-}, \mathrm{HCO}_{4}^{-}\right)$ions and $\mathrm{HCO}_{3}^{-}$in ion-exchange resins will depend on the relative ion selectivities of the resins.

In a soil-resin-solution system, as distinct from a resin-solution system, the difficult question to resolve is whether the intraparticle diffusion limitation is within the resins or soil aggregates or particles. The data from this study did not directly answer this question. However, a number of inferences can be derived from the data. For $D \pi^{2} / r_{0}^{2}$ to be constant for each experimental $Q / Q_{\infty}$ value (Table 4 ), $r_{0}$ has to be fairly constant, as would be expected for the resin beads compared with soil aggregates or particles. If diffusion within the resins was a rate-limiting step, the rate parameter $D \pi^{2} / r_{0}^{2}$ (Table 4 ) and or $k_{\mathrm{d}}$ (Table 3 ) should not vary drastically with shaking (Petruzzelli et al., 1991). Actually, in Soil 1 and Soil $4, k_{\mathrm{d}}$ or $D \pi^{2} / r_{0}^{2}$ values were reasonably close for the shaking and nonshaking. Thus, the rate-limiting step, in this case, appeared to be intraparticle diffusion within the resins.

The deviation in $D \pi^{2} / r_{0}^{2}$ or $k_{\mathrm{d}}$ for Soil 2 and Soil 3 
Table 3. Goodness-of-fit statistics and the rate parameters $t$ of three kinetic models fitted to phosphate release determined by phosphate sorption by mixed-ion exchange resins from some tropical soils.

\begin{tabular}{|c|c|c|c|c|c|c|c|c|c|}
\hline \multirow[b]{2}{*}{ Soil } & \multicolumn{3}{|c|}{ Film diffusion model (Eq. [1]) } & \multicolumn{3}{|c|}{ Apparent first model (Eq. [4]) } & \multicolumn{3}{|c|}{ Parabolic model (Eq. [6]) } \\
\hline & $\boldsymbol{R}^{2}$ & SE & $k_{d} \times 10^{-5}$ & $R^{2}$ & SE & $k_{\mathrm{e}} \times 10^{-5}$ & $\boldsymbol{R}^{2}$ & SE & $k_{\mathrm{d}} \times 10^{-3}$ \\
\hline \multicolumn{10}{|c|}{ Nonshaking } \\
\hline Soil 2 & 0.984 & 0.058 & 0.97 & 0.984 & 0.048 & 0.97 & 0.992 & 0.041 & 1.80 \\
\hline Soil 3 & 0.963 & 0.070 & 1.19 & 0.963 & 0.070 & 1.19 & 0.993 & 0.035 & 1.87 \\
\hline Soil 4 & 0.939 & 0.097 & 1.94 & 0.939 & 0.097 & 1.94 & 0.997 & 0.024 & 2.68 \\
\hline Soil 2 & 0.975 & 0.053 & 2.97 & 0.975 & 0.053 & 0.97 & 0.997 & 0.025 & 2.93 \\
\hline Soil 3 & 0.952 & 0.075 & 2.44 & 0.952 & 0.075 & 1.19 & 0.990 & 0.047 & 2.75 \\
\hline Soil 4 & 0.919 & 0.098 & 2.86 & 0.919 & 0.098 & 1.94 & 0.990 & 0.049 & 2.82 \\
\hline
\end{tabular}

$\uparrow k_{\mathrm{d}}$ and $k_{\mathrm{e}}$ are in $\mathrm{mg} \mathrm{P} \mathrm{dm} \mathrm{ds}^{-1}$, and $k_{\mathrm{d}}$ for parabolic model is $\mathrm{mg} \mathrm{dm}^{-3} \mathrm{~s}^{-1}$. All $R^{2}$ values significant at $P=0.01$.

between shaking and nonshaking might be due to higher initial rates of $P$ release than the rate of diffusion across the bounding film at the resin exchanger surfaces. This would make film diffusion rate limiting or the ratecontrolling step at the early stages of the exchange reactions, especially at $t<2 \mathrm{~h}$ (Sposito, 1989; Helfferich, 1962) until an equilibrium between the rate of release and diffusion across the films was established. Thereafter, intraparticle diffusion apparently became the ratelimiting step in the exchange reactions.

Under nonshaking conditions, however, both filmand intraparticle diffusion can be rate limiting for ionexchange reaction (Ogwada and Sparks, 1986) because of the development of large films around the resin particles. Implicit in the particle diffusion equation [Eq. 5] is that the rate parameter $D \pi^{2} / r_{0}^{2}$ determines the time to achieve a given fraction of equilibrium $\left(F=Q / Q_{\infty}\right)$, which varies inversely with $r_{0}^{2}$ (Boyd et al., 1947). Under nonshaking conditions, $r_{0}$ would tend to increase because of the bounding films around the resin beads, and thus reduce $D \pi^{2} / r_{0}^{2}$ for the nonshaking in contrast to shaking conditions.

\section{Activation Energies and Thermodynamic Parameters}

The temperature-dependent $P$ release rates plotted as a function of the reciprocal of absolute temperature (I/T) yielded Arrhenius linear relations (Fig. 3). The activation energies $E_{\mathrm{a}}$ deduced from the slopes of the Arrhenius plots are given in Table 5. Activation energy is a measure of the energy to be overcome, and thus can be interpreted as the relative index of the binding strength of phosphate ions. Thus, the relatively low $E_{\text {a }}$ for Soil 2 and Soil 3 indicated relatively less rigid binding and rapid release compared to Soil 1 and Soil 4 .

The magnitude of $E_{\mathrm{a}}$ is a useful parameter for differentiating intraparticle from film diffusion-controlled ion-exchange reactions (Boyd et al., 1947; Sparks, 1985). Activation energies ranging from 17 to $21 \mathrm{~kJ} \mathrm{~mol}^{-1}$ suggest a film diffusion-controlled ion-exchange reaction, while $E_{\mathrm{a}}$ ranging from 21 to 42 suggests an intraparticle diffusion mechanism (Boyd et al., 1947; Sparks, $1985)$. The $E_{\mathrm{a}}$ values in this study are thus consistent with intraparticle diffusion mechanism.

The $\Delta H^{\mathrm{O} \ddagger}$ of activation is a measure of the amount

Table 4. The fractional equilibrium $F$, the rate parameter $\left(D \pi^{2} t / r_{0}^{2}\right) \times 10^{-5} \mathrm{~s}^{-1}$, and the diffusion coefficient $D \times 10^{-13} \mathrm{~m}^{2} \mathrm{~s}^{-1}$ of the particle diffusion model (Eq. [5]) for describing the kinetics of $P$ release determined by $P$ sorption by mixed cation-anion exchange resins from tropical soils under shaking and non-shaking condition.

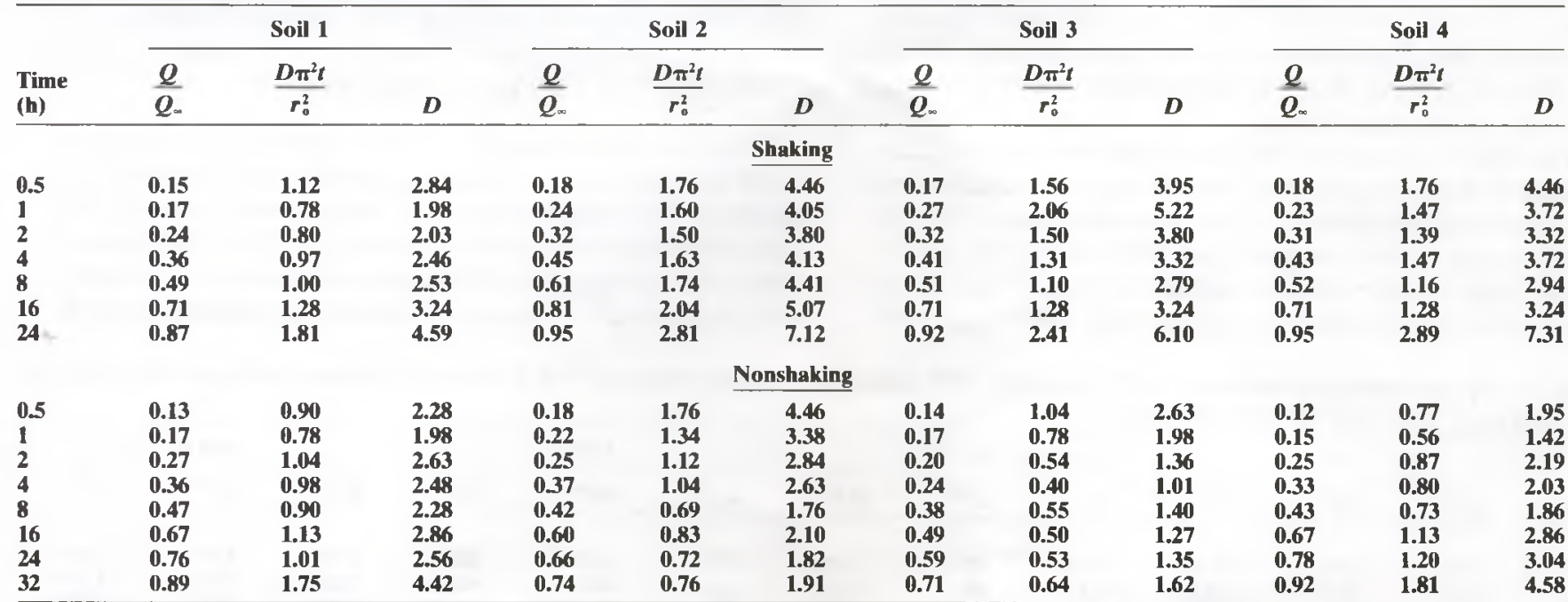

† Values of $D \pi^{2} t / r_{0}^{2}$ in the region of $F>0.80$ are unreliable because of large experimental errors in this region (Boyd et al., 1947). 


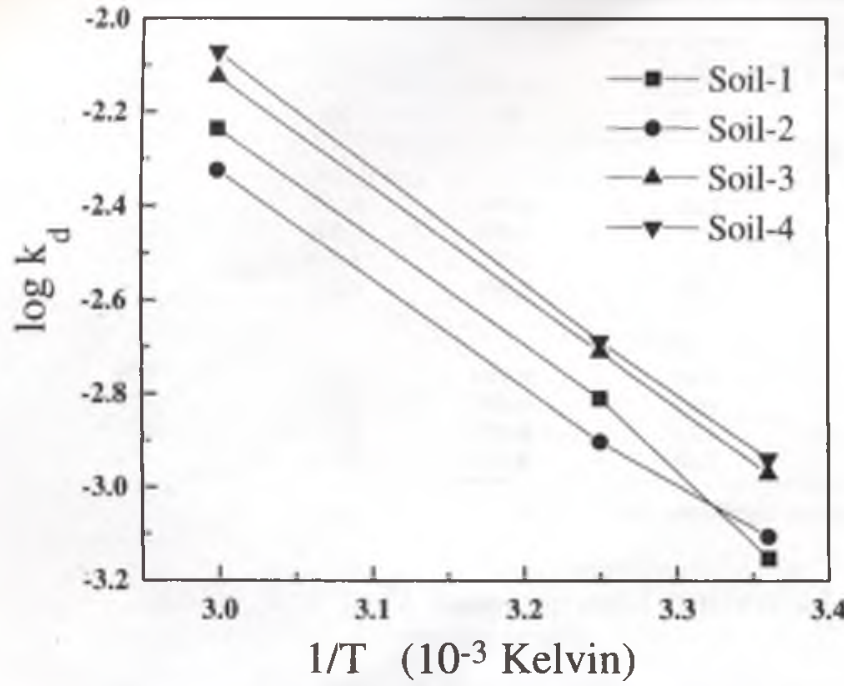

Fig. 3. The influence of temperature on rate coefficients of $P$ release from tropical soils determined by mixed cation-anion exchange resins as described Arrhenius equation.

of heat energy gained or lost in transferring $\mathrm{P}$ from the soil through solution to form an activated surface complex on the resins (Griffin and Jurinak, 1974). The $\Delta H^{\text {(0) }}$ values were positive (Table 6) and close to those reported for $\mathrm{P}$ interaction calcite by Griffin and Jurinak (1974). The positive $\Delta H^{\mathrm{O} \ddagger}$ values seemed to indicate that $P$ exchange reactions with resin exchange surfaces required considerable net heat absorption. Helfferich indicated that the heat gained or lost in the course of anion exchange reaction is approximately 8 to $9 \mathrm{~kJ} \mathrm{~mol}^{-1}$. Consequently, Taylor and Ellis (1978) proposed that consumption of heat for $\mathbf{P}$ exchange reactions in Dowex1-X8 resins in excess of 8 to $9 \mathrm{~kJ} \mathrm{~mol}^{-1}$ suggested the formation of double electrostatic bonds between $P$ and the resin exchange surfaces. The $\Delta H^{\mathrm{O} \ddagger}$ values, far in excess of 8 to $9 \mathrm{~kJ} \mathrm{~mol}^{-1}$ in this study, suggested that $\mathrm{HPO}_{4}^{2-}$ might be the predominantly sorbed ion. This can be further deduced from the equilibrium $\mathrm{pH}$ determined for the soil-resin-solution after agitation. The mean $\mathrm{pH}$ of the soil-resin-solution was $7.5+0.1$ for Soil 1,7.6 +0.2 for Soil 2 , and $7.2+0.0$ and $7.3+0.0$ for Soil 3 and Soil 4, respectively, after shaking for 16 to $24 \mathrm{~h}$, suggesting that the predominant ions diffusing into the resins were $\mathrm{HPO}_{4}^{2-}$.

The $\Delta G^{\mathrm{O} \ddagger}$ of activation, a relative measure of the change in free energy from free $\mathbf{P}$ state to an activated $P$ complex on the surface of the resin adsorbents (Griffin and Jurinak, 1974), ranged from 92.0 to $98.4 \mathrm{~kJ} \mathrm{~mol}^{-1}$. These values were slightly higher than $\Delta G^{\mathrm{o} \neq}$ for $\mathrm{P}$ adsorption by calcite (Griffin and Jurinak, 1974) probably
Table 5. The $R^{2}$ values, intercept, and slope parameters of the linear Arrhenius equation, and the energy of activation $E_{\text {a }}$ of phosphate release determined by mixed cation-anion exchange resins from tropical soils.

\begin{tabular}{lcccc}
\hline Soil & Ln $\boldsymbol{A}$ & Slope & \multicolumn{1}{c}{$\boldsymbol{R}^{\mathbf{2}}$} & \multicolumn{1}{c}{$\boldsymbol{E}_{\mathbf{a}}$} \\
\hline & & & & $\mathrm{kJ} \mathrm{mol}^{-1}$ \\
Soil 1 & $\mathbf{8 . 3 1 4}$ & $-\mathbf{5 8 6 0 . 5}$ & $\mathbf{0 . 9 9 9 9 * *}$ & $\mathbf{4 8 . 7 2}$ \\
Soil 2 & $\mathbf{5 . 7 0 2}$ & $-\mathbf{5 0 5 4 . 6}$ & $\mathbf{0 . 9 9 9 3 *}$ & $\mathbf{4 2 . 0 3}$ \\
Soil 3 & $\mathbf{7 . 2 5 3}$ & $-\mathbf{5 4 1 2 . 4}$ & $\mathbf{0 . 9 9 9 9 * *}$ & $\mathbf{4 5 . 0 0}$ \\
Soil 4 & $\mathbf{7 . 8 4 9}$ & $-\mathbf{5 5 7 2 . 5}$ & $\mathbf{0 . 9 9 9 9 * *}$ & $\mathbf{4 6 . 3 3}$ \\
\hline
\end{tabular}

* Significant at the 0.05 probability level.

** Significant at the 0.01 probability level.

because of rapid reactions between $\mathrm{Ca}^{2+}$ and $\mathrm{P}$ ions in that šystem. But the $\Delta G^{\text {oł }}$ values were, however, lower than $\Delta G^{\text {O }}$ for $\mathrm{P}$ sorption by resin bags in some temperate soils (Yang and Skogley, 1992).

The values of $\Delta \boldsymbol{S}^{\mathrm{O} \ddagger}$ of activation were relatively low and negative (Table 4). The negative entropy change can be attributed to restricted or constrained movement imposed by the binding of $\mathbf{P}$ ions to exchange sites in the resins (Lasaga, 1981). The $\Delta S^{\mathrm{O}}$ for $\mathrm{P}$ uptake by the mixed resins from these soils was lower than $P$ sorption by calcite (Griffin and Jurinak, 1974) probably because of the high activity of $\mathrm{Ca}^{2+}$ in that system. Similarly, the

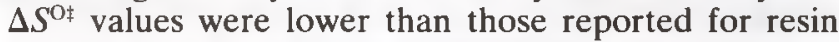
bags by Yang and Skogley (1992), indicating a relatively low degree of stearic inhibition between the $\mathrm{P}$ ions and the resin reactive surfaces.

Perhaps, differences in resin characteristics and selectivity of $\mathbf{P}$ ions would partly account for the variation in $\Delta S^{\mathrm{O} \ddagger}, \Delta H^{\mathrm{O} \ddagger}$, and $\Delta G^{\mathrm{O} \ddagger}$ for $\mathrm{P}$ exchange reactions with resin surfaces in this study from the values reported by Yang and Skogley (1992). Further, the P ions apparently diffusing to the resins in our study seemed to be mostly $\mathrm{HPO}_{4}^{2-}$ ions as deduced from the equilibrium $\mathrm{pH}$. Ionic size increases from $\mathrm{H}_{2} \mathrm{PO}_{4}^{-}$to $\mathrm{HPO}_{4}^{2-}$; hence an increasingly positive entropy might be required to partially overcome the increased activation energy in order to increase the self-diffusion coefficient of $\mathrm{HPO}_{4}^{2-}$ (Soldano and Boyd, 1953). Thus, the possible occurrence of positive $\Delta S^{\mathrm{O}}$ with $\mathrm{HPO}_{4}^{2-}$ diffusion would serve to make $\Delta S^{0 \ddagger}$ less negative and $\Delta H^{\mathrm{O} \ddagger}$ larger and more positive than those reported in Yang and Skogley (1992).

\section{CONCLUSIONS}

Phosphorus release kinetics from the soils determined by $\mathrm{P}$ sorption to mixed resins conformed to diffusion models. The magnitude of $E_{\mathrm{a}}$ was greater than $E_{\mathrm{a}}$ for film diffusion controlled exchange reaction, but consistent with intraparticle diffusion mechanism. Our results also suggested that under nonshaking conditions, both

Table 6. The free energy of activation $\Delta G^{0 \ddagger}$, enthalpy $\Delta H^{01}$ and entropy of activation $\Delta S^{0 \ddagger}$ of $P$ release as determined by mixed cationanion exchange resins from the soils. $\dagger$

\begin{tabular}{|c|c|c|c|c|c|c|c|c|c|c|c|c|}
\hline \multirow[b]{2}{*}{ Temp } & \multicolumn{3}{|c|}{ Soil 1} & \multicolumn{3}{|c|}{ Soil 2} & \multicolumn{3}{|c|}{ Soil 3} & \multicolumn{3}{|c|}{ Soil 4} \\
\hline & $\Delta G^{\mathbf{0} \neq}$ & $\Delta \boldsymbol{H}^{\boldsymbol{0}_{\mathrm{x}}}$ & $\Delta \boldsymbol{S}^{\mathrm{o}_{\mathrm{r}}}$ & $\Delta G^{\mathbf{0} \neq}$ & $\Delta H^{0}$ & $\Delta \boldsymbol{S}^{\mathbf{0} \neq}$ & $\Delta G^{\mathbf{0} \neq}$ & $\Delta \boldsymbol{H}^{\mathbf{0}}$ & $\Delta \boldsymbol{S}^{\circ \mathrm{t}}$ & $\Delta G^{0 \pm}$ & $\Delta H^{0 z}$ & $\Delta S^{0 *}$ \\
\hline $\mathbf{K}$ & & & & & & & & & & & & \\
\hline 298 & 93.1 & 47.3 & -153.7 & 92.8 & 40.5 & -175.5 & 92.0 & 43.5 & -162.8 & 91.8 & 43.9 & -160.7 \\
\hline 333 & 98.2 & 47.0 & -153.8 & 98.7 & 40.2 & -175.7 & 97.4 & 43.2 & -162.8 & 98.4 & 43.6 & -164.6 \\
\hline
\end{tabular}

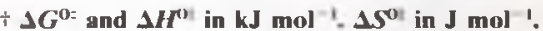


film diffusion and intraparticle diffusion limitation seemed to occur, while under shaking or agitation intraparticle diffusion appeared to be the rate-limiting step.

Intraparticle diffusion limitation in the resins with shaking, which is the standard resin P extraction method for fertilizer-P calibration and recommendation in these soils, implies that there can be no single value for resin extractable in a soil without specifying the type of resins because of possible differences in resin physical characteristics.

\section{ACKNOWLEDGMENTS}

The authors are grateful to the Brazilian Research Council for Scientific and Technological Development (CNPq) for research fellowship to Institute of Agronomy, Campinas (IAC), and the Third World Academy of Sciences (TWAS), Trieste, Italy, for travel support for one of us (JOA). We thank Dr. G. Adamian AVH Research Fellow, Institute of Theoretical Physics, University of Giessen, Germany, for solution to Eq. [5]. We also thank the Institute of Soil Science, University of Giessen, for allowing one of us to repeat some aspects of this study.

\section{REFERENCES}

Adamson, A.W. 1969. Understanding physical chemistry. W.A. Benjamin, New York, NY.

Agbenin, J.O., C.A. De Abreu, and B. van Raij. 1999. Extraction of phytoavailable trace metals from tropical soils by mixed ion exchange resins modified with inorganic and organic ligands. Sci. Total Environ. 227:187-196.

Agbenin, J.O., and B. van Raij. 1999. Rate processes of calcium, magnesium and potassium desorption from variable-charge soils by mixed ion exchange resins. Geoderma 93:141-157.

Aharoni, C., and D.L. Sparks. 1991. Kinetics of soil chemical reactions-A theoretical treatment. p. 1-18. In D.L. Sparks and D.L. Suarez (ed.) Rates of soil chemical processes SSSA Spec. Publ. 27. SSSA, Madison, WI.

Amer, F.D., D.R. Bouldin, C.A. Black, and F.R. Duke. 1955. Characterization of soil phosphorus by anion exchange resin adsorption and ${ }^{32} \mathrm{P}$ equilibration. Plant Soil 6:391-408.

Bache, B.W., and C. Ireland. 1980. Desorption of phosphate from soils using anion exchange resins. J. Soil Sci. 31:297-306.

Boyd, G.E., A.W. Adamson, and L.S. Myers. 1947. The exchange adsorption of ions from aqueous solutions by organic zeolites: II. Kinetics. J. Am. Chem. Soc. 69:2836-2848.

Bruemmer, G.W., J. Gerth, and G.K. Tiller. 1988. Reaction kinetics of the adsorption and desorption of nickel, zinc and cadmium by goethite. I. Adsorption and diffusion of metals. J. Soil Sci. 39:37-52.

Crank, J. 1975. The mathematics of diffusion. Oxford University Press, London, UK.
Dalal, R.C. 1974. Desorption of phosphate by anion exchange resin. Commun. Soil Sci. Plant Anal. 5:531-538.

Griffin, R.A., and J.J. Jurinak. 1974. Kinetics of phosphate interactions with calcite. Soil Sci. Soc. Am. Proc. 38:75-79.

Helfferich, F.G. 1962. Ion exchange. McGraw-Hill Book Co., New York, NY.

Keay, J., and A. Wild. 1961. The kinetics of cation exchange in vermiculite. Soil Sci. 92:54-60.

Laidler, K.J. 1965. Chemical kinetics. McGraw Hill, New York, NY.

Lasaga, A.C. 1981. Transition state theory. p. 135-169. In A.C. Lasaga and R.J. Kirkpatrick (ed.) Reviews in mineralogy. Vol. 8: Kinetics of geochemical processes. Mineralogical Society of America, Washington, DC.

McKeague, J.A., and J. Day. 1966. Dithionite and oxalate extractable iron and aluminum as aids in differentiating various classes of soils. Can. J. Soil Sci. 46:13-22.

Mehra, O.P., and M.L. Jackson. 1960. Iron oxide removal from soils and clays by a dithionite citrate system buffered with sodium bicarbonate. Clays Clay Miner. 7:313-317.

Murphy, J., and J.P. Riley. 1962. A modified single solution for the determination of phosphorous in natural waters. Anal. Chim. Acta 27:31-36.

Nye, P.H. 1979. Diffusion of ions and uncharged solutes in soils and soil clays. Adv. Agron. 31:225-272.

Page, A.L., R.H. Miller, and D.R. Keeney. 1982. Methods of soil analysis. Part 2. 2nd ed. Agron. Monogr. 9. ASA and SSSA, Madison, WI.

Petruzzelli, D., F.G. Helfferich, and L. Liberti. 1991. Ion exchange kinetics on reactive polymers and inorganic soil constituents. $p$ 95-118. In D.L. Sparks and D.L. Suarez (ed.) Rates of soil chemical processes SSSA Spec. Publ. 27. SSSA, Madison, WI.

Robinson, J.S., J.K. Syers, and N.S. Bolan. 1992. Importance of proton supply and calcium sink in the dissolution of phosphate rock materi. als of different reactivity. J. Soil Sci. 43:447-459.

Ogwada, R.A., and D.L. Sparks. 1986. Kinetics of ion exchange on clay minerals and soils: 1 . Evaluation of methods. Soil Sci. Soc Am. J. 50:1158-1162.

Skopp, J. 1986. Analysis of time-dependent chemical processes in soils. J. Env. Qual. 15:205-213.

Soldano, B.A., and G.E. Boyd. 1953. Self-diffusion in strong-bave anion exchangers. J. Am. Chem. Soc. 75:6099-6104.

Sparks, D.L. 1985. Kinetics of ionic reactions in clay minerals and soils. Adv. Agron. 38:231-266.

Sposito, G. 1989. The chemistry of soils. Oxford University Pren. New York, NY.

Taylor, R.W., and B.W. Ellis. 1978. A mechanism of phosphate adsorption on soil and anion exchange resin surfaces. Soil Sci. Soc. Am. J. 42:432-436.

Vaidyanathan, L.V., and O. Talibudeen. 1970. Rate processes in the desorption of phosphate from soils. J. Soil Sci. 21:173-183.

van Raij, B., J.A. Quaggio, and N.M. Silva. 1986. Extraction of phosphorus, potassium, calcium and magnesium by an ion exchange procedure. Commun. Soil Sci. Plant Anal. 17:547-566.

Yang, J.E., and E.O. Skogley. 1992. Diffusion kinetics of multinutricnt extraction by mixed-bed ion exchange resin. Soil Sci. Soc. Am. J. 56:408-414. 